\title{
O Desvalor da Conduta como Critério de Identificação da Insignificância para Aplicação do Princípio de Intervenção Mínima
}

\author{
Paulo César Busato ${ }^{1}$
}

Resumo: Trata-se de um trabalho que foca criticamente a postura das Cortes Superiores no que tange à interpretação do chamado princípio da insignificância ou princípio da intervenção mínima. Expõe a forma pela qual o Supremo Tribunal Federal e o Superior Tribunal de Justiça vêm utilizando o mencionado princípio, apresentando os critérios utilizados pelas Cortes, com especial foco na ideia de mínima ofensividade da conduta. Propõe-se a adoção de um conceito significativo de ação, cuja expressão de sentido conduz a uma ideia de pretensão normativa de ofensividade capaz de representar a globalidade do sentido do princípio discutido. Finalmente, à luz dessa concepção, apresenta-se uma crítica e uma proposta de delimitação mais precisa dos critérios de aplicação do princípio.

Palavras-chave: Princípio de intervenção mínima. Ofensividade da conduta. Conceito significativo de ação.

\begin{abstract}
This is a work that focuses critically on the stance of the High Courts in regard to the interpretation of the so called principle of insignificance or principle of minimum intervention. It exposes the way in which the Supreme Court and Superior Court have been using the said principle, with the criteria used by the courts, with particular focus on the idea of minimal offensiveness of the conduct. It is proposed to adopt a meaningful concept of action, whose expression leads to a sense of the idea of normative intent of offensiveness able to represent the overall sense of the principle discussed. Finally, in light of this conception, it presents a critique and a proposal for a more precise delimitation of the criteria for applying the principle.
\end{abstract}

Keywords: Principle of minimum intervention. Offensiveness of the conduct. The significant action concept.

1 Doutor em Problemas Atuais do Direito Penal pela Universidade Pablo de Olavide (Espanha). Professor de Direito Penal da Universidade Federal do Paraná e da FAE - Centro Universitário Franciscano; Professor convidado da Universidad Politécnica de Nicarágua e dos programas de doutorado da Universidad de Buenos Aires e da Universidad Pablo de Olavide.E-mail: pbusato2005@yahoo.com.

Recebido em: 03/12/2010.

Revisado em: 21/12/2010.

Aprovado em: 11/01/2011. 


\section{Introdução}

Não é de hoje que o Supremo Tribunal Federal tem preferido adotar o princípio de intervenção mínima como critério de identidade da dimensão material do tipo. Ao assim agir, nossa Suprema Corte não faz mais do que seguir uma tendência universalmente difundida acerca da qual o Direito penal não é instrumental destinado a intervir mediante a existência de uma violação meramente formal da norma posta.

Essa posição, porque difundida pela doutrina e jurisprudência, já está a salvo de qualquer discussão. O mesmo não se pode dizer, porém, dos critérios empregados para a identificação das situações concretas de incidência do referido princípio, o qual, não raras vezes, vem atrelado à ideia de insignificância, equivocadamente alçada à condição de princípio. Ali reside a nova fronteira de discussão teórica e o objeto do presente estudo.

Tomando por base as reiteradas decisões do Supremo Tribunal Federal, com reflexos nas demais instâncias de julgamento, pretende-se aqui, a partir de um modelo jurídico-penal próprio de um Estado social e democrático de direito, fazer um estudo crítico especialmente focado na ideia do desvalor da conduta como um dos critérios que tem sido levado em consideração para a identificação das hipóteses de incidência do princípio de intervenção mínima como forma de infirmar a materialidade do tipo.

\section{As Funções dos Princípios Limitadores da Intervenção Penal no Estado Social e Democrático de Direito}

A discussão ao redor dos princípios como espécie normativa tem ocupado os teóricos da argumentação, com vistas especialmente ao estabelecimento de critérios de resolução dos conflitos destes com as regras ou entre os próprios princípios, conforme Rothenburg (1999, p. 33).

Sem descurar da evidente importância de tais discussões, há um aspecto prévio, muitas vezes negligenciado pelos próprios teóricos do direito que, no entanto, certamente condiciona as escolhas a respeito do melhor perfil teórico a ser adotado a respeito dos princípios jurídicos: 
sua dimensão política. Nesse sentido, cabe citar o comentário de Ferrajoli (2004, p. 117): “[...] as definições teóricas, com efeito, são definições convencionais, cuja aceitação depende de sua idoneidade para satisfazer as finalidades explicativas que perseguem".

Com efeito, toda discussão sobre princípios envolve uma questão política obrigatória. Isto porque qualquer organização social pressupõe, necessariamente, o estabelecimento de relações de poder que se estabelecem obrigatoriamente mediante normas baseadas na ideia central de cogência determinada pela autoridade, segundo Ferraz Júnior (1997, p. 67)².

Essa questão é básica na estrutura da vida humana gregária, na qual o homem se interrelaciona e, necessariamente, uma estrutura normativa se estabelece. É impossível, de acordo com Mayer (2000, p. 55), viver em sociedade sem normas, pois são estas que permitem a própria organização social.

Entretanto, se o estabelecimento de alguma norma é uma situação atávica e inevitável, o mesmo não se pode dizer a respeito da escolha das normas que vão reger a relação social em questão. De fato, a escolha das normas de regência de uma sociedade certamente reflete seu perfil estrutural, a forma pela qual se estruturam as relações de poder.

É importante perceber aqui que não se está mencionando a norma posta, positivada. Não ainda. A organização social não depende da norma positiva, por muito esforço que façam nesse sentido as viúvas de Kelsen. A estrutura política, baseada nas relações de poder, cria normas de convivência independentemente da estrutura jurídica. O modelo consuetudinário é prova cabal disso.

A escolha política aqui referida, diz respeito a diretrizes interpretativas da rede de interrelações sociais e do papel do Estado dentro dessa

2 A cogência aqui referida é a preservação da relação de autoridade em sentido comunicativo, independente do cumprimento efetivo da norma, conforme bem explica Ferraz Júnior: a relação de autoridade se define pela garantia estabilizada de que certas expectativas devem prevalecer, independentemente de o comportamento exigido ocorrer ou não. O importante para o cometimento normativo não é o cumprimento efetivo do relato (uma norma pode ser desobedecida e, apesar disso, a relação de autoridade permanece), mas a garantia de que reações que desqualificam a autoridade, como tal, estão excluídas da situação comunicativa. 
estrutura. Resulta, pois, que a escolha dessas normas, conquanto seja socialmente livre - entendida assim a ideia de que a sociedade as determina independentemente das amarras do Estado e do direito positivo - é o que determina o perfil político de uma sociedade. Em outro dizer, as estruturas condicionantes das relações sociais refletirão obrigatoriamente a distribuição social de poder e desenharão um perfil político mais alinhado a uma ideia de liberalismo ou voltado para um perfil totalitário.

Essa identidade social certamente reverbera na organização do Estado, no perfil de governo (democracia ou ditadura) e também na escolha da estruturação jurídica. As regras jurídicas, inclusive a própria norma fundamental política - leia-se, Constituição - virão impregnadas da identidade social que lhes é fundante. Daí a óbvia reticência e a necessária resistência à remessa de toda a matéria controversa relativa aos conflitos jurídicos que exigem uma solução principiológica à Constituição. Tratase de postura, no mínimo, reducionista. É necessário ir além.

É claro que nessa transposição da Constituição para a estrutura fundante da sociedade, a história da civilização conquanto revele uma permanente evolução dos seres humanos, também demonstrou que tem se dado através de um movimento pendular que, por vezes, impõe retrocessos. De todo modo, esses retrocessos episódicos jamais tardam em refletir-se em normas jurídicas, inclusive em normas jurídicas fundantes, razão pela qual, volta-se a afirmar a ilusão representada pela pretensão de segurança jurídica.

Desse quadro, resulta fundamental pensar a organização social e, de consequência, a estruturação do seu controle, a partir de princípios informativos que representem a escolha política de uma determinada sociedade em certo grau de desenvolvimento histórico.

Assim, todo o controle jurídico-normativo resta submetido a uma carta de princípios, a qual positivada ou não, condicionará toda a interpretação das estruturas de controle social, inclusive aquela exercida juridicamente.

No atual estágio de desenvolvimento da humanidade, não é aceitável pensar em outro formato de organização social estruturada que não o Estado social e democrático de Direito. É por isso que essa expressão 
política há de estar contemplada em todo o ordenamento jurídico como molde condicionante.

Assim, temos que no Direito penal esse desenho compõe o arcabouço normativo sob a forma de princípios, os quais, seja em virtude de sua própria logicidade, como orienta Dworkin (apud DWORKIN, 2002) ou de sua maior densidade semântica, conforme Alexy (2002), impõem-se sobre as regras jurídicas.

O controle social penal é exercido por regras positivas e negativas. Regras que impõem ou proíbem condutas, sob sanção - tipos de ação ou omissão - e regras que permitem a composição de exceções ao arbítrio do controle - justificações e exculpações.

Diante das premissas lançadas, porém, é forçoso reconhecer que, sejam quais forem essas regras deverão ceder em eventual conflito com os princípios orientadores do modelo de Estado social e democrático de Direito.

O Estado de Direito, como estrutura jurídica condicionante do despotismo impõe a submissão à lei através do princípio de legalidade. Por sua vez, o Estado social, há de ser entendido como Estado provedor do Wellfare State, ou seja, um Estado atento aos clamores públicos, mas também essencialmente liberal; capaz de cobrir as necessidades básicas dos cidadãos, sempre com o mínimo de intervenção sobre sua liberdade. Em suma, um Estado que tem deveres a cumprir na proteção dos cidadãos, porém, atuando com o mínimo de custo social. Esse perfil, em termos de controle social penal, corresponde ao princípio de intervenção mínima. Finalmente, o Estado democrático é aquele que respeita a capacidade de os próprios cidadãos estabelecerem e decidirem o próprio destino, ou seja, trata-se do Estado que não esquece a razão fundamental de sua existência: os cidadãos nele representados. Esse Estado se obriga a respeitar as individualidades, ficando obrigado a oferecer a cada um o reconhecimento estatal de sua individualidade, o que somente é possível, no controle social penal, através do estreito respeito ao princípio de culpabilidade, de acordo com Busato e Huapaya (2007, p. 119). 


\section{Insignificância ou Intervenção Mínima?}

Evidentemente, o controle social penal não pode afastar-se do princípio de intervenção mínima como imposição do Estado social. E isso até por conta de seu imediato reflexo na necessidade de afirmação de uma dimensão material do tipo.

É fácil perceber a relação específica entre o Estado social e a intervenção mínima. Basta perceber que enquanto o Estado brasileiro assumiu um papel intervencionista, desocupado das necessidades ditadas por cada um, impondo a partir de um governo central o que deve ser a escala de prioridades sociais - sem meias palavras, a referência aqui é à ditadura militar - o modelo jurídico-penal esteve completamente afastado da ideia de discutir uma dimensão material do tipo.

O cenário de publicações, o ambiente acadêmico e o cotidiano forense responderam durante mais de vinte anos a uma ideia de dura lex sed lex, baseada na (falsa) presunção de que o Estado tinha conhecimento do que era bom para o cidadão, inexistindo, portanto, qualquer espaço para discussão sobre tipicidade material. O perfil principiológico era outro. Não se podia falar em dimensão material para justificar intervenção penal. A intervenção penal existia, como tudo o mais, somente porque a incriminação da conduta estava disposta na lei. Tratava-se, simplesmente, de cumprir a lei e não interpretá-la; de efetuar, portanto, a mera subsunção típica.

O processo de abertura política, refletido na estrutura de princípios condicionantes da interpretação normativa, provocou a transformação que vivemos hoje tanto no cenário acadêmico, com farto intercâmbio com as matrizes de pensamento jurídico e amplo volume de publicações livres, quanto no ambiente forense, com a progressiva, ainda lenta, mas inarredável transformação da discussão jurídica, com efeitos evidentes na hermenêutica e na efetiva prestação jurisdicional. 
É nesse contexto que, de modo incipiente e terminologicamente criticável $^{3}$, tem chegado ao Supremo Tribunal Federal a discussão a respeito dos limites materiais de intervenção penal ditados pela exigência de uma expressão material dos tipos.

Já é irreversível a exigência de que a imposição de uma intervenção jurídico-penal tenha por base não apenas um processo subsuntivo, mas inclua necessariamente uma expressão de aflição a um bem jurídico fundamental para o desenvolvimento do ser humano em sociedade.

Aquilo que era matéria assentada há tempos em outros países que viveram o liberalismo político em etapa anterior, como na Europa Ocidental, hoje tem franca aceitação também no Brasil ${ }^{4}$.

Nesse contexto, com nomenclatura variada (princípio de intervenção mínima, princípio de insignificância, princípio de bagatela), tem sido fartamente admitido pela praxis forense, especialmente das Cortes Superiores $^{5}$, que é exigível, para a existência de um tipo penal, que um bem jurídico essencial para o desenvolvimento do ser humano em sociedade tenha sido atingido de modo grave e irreparável por outra via de controle social menos gravosa.

3 A crítica terminológica ao emprego da expressão princípio da insignificância é derivada da falsa impressão passada pelo termo, porquanto a insignificância, na hipótese, qualifica o princípio de modo a transmitir uma ideia de que se cuida de um princípio que tem como objeto aspectos penais insignificantes e, portanto, sua aplicabilidade não é de somenos importância. Na verdade, trata-se de um princípio estruturante do Estado social, razão pela qual deve ser tomado em seu verdadeiro sentido, qual seja, de redução da intervenção penal ao seu mínimo (daí a ideia de princípio de intervenção mínima), atuando em situações em que a ofensa aos bens jurídicos resulta socialmente de escassa magnitude.

4 Com efeito, a discussão sobre o princípio de intervenção mínima, que figurava já nos trabalhos dos anos 60 e 70 na Europa, somente obteve espaço em publicações e repercussão forense no Brasil a partir da abertura política do final dos anos 80 e só atingiu um patamar expressivo e penetração acadêmica na última década.

5 Por exemplo, no STF: HC n ${ }^{\circ}$ 84.412/SP, Min. Celso de Mello, publicado no DJ de 19/11/2004 e HC 96307/GO, Min. Joaquim Barbosa, publicado no DJ 11/12/2009 e no STJ, HC 126859/ MS, Ministro Arnaldo Esteves, publicado no DJ de 07/12/2009 e RHC 26661/MG, Ministro Jorge Mussi, publicado no DJ de 30/11/2009. 
Essa questão não é mais discutível. O problema agora passa a ser outro, especificamente o de estabelecer em que casos essa tipicidade material efetivamente merece ser reconhecida.

É nesse particular que ganha interesse apreciar a forma pela qual o Supremo Tribunal Federal tem se posicionado a respeito, mormente quando se identifica que suas decisões, invariavelmente, têm servido de baliza cega na aplicação do direito por outras instâncias de decisão.

\section{Os Critérios do Supremo Tribunal Federal para Aferição da Incidência do Princípio de Intervenção Mínima (o paradigma do HC 84.412-0 SP)}

Sem embargo de toda a crítica que se faz a ideia de segurança jurídica, é certo que todo sistema de aplicação de normas deve ser coerente e atento à observância de regramentos básicos que permitam uma mínima previsibilidade. A aplicação do direito criminal no âmbito nacional, entretanto, constantemente surpreende pela sua absoluta imprevisibilidade e, não raras vezes, pela coexistência incompreensível de decisões díspares para situações análogas. É o caso da aplicação do chamado "princípio" da insignificância pelos Tribunais pátrios.

Com efeito, basta uma pesquisa jurisprudencial entre os diversos Tribunais brasileiros, assim como no âmbito interno de cada um dos Tribunais, para que se verifique o quão desiguais costumam ser os "critérios" utilizados. O que se identifica é que em nossos Tribunais não há qualquer coerência na aplicação da referida regra. Ora inexistem critérios, ora se elencam critérios; quando estes são elencados, por vezes, ignora-se no que os mesmos efetivamente consistiriam. Pior, embora haja decisões que se lastreiem em tais critérios, não é raro se fundamentarem em circunstâncias que não se subsumem aos ditos critérios ${ }^{6}$.

6 Neste sentido: HC 135.451/RS. Rel. Min. Laurita Vaz. j.15.09.2009; REsp 1.112.241/ SC. Rel. Min. Maria Thereza de Assis Moura. j.25.08.2009; HC 129.226/SP. Rel. Min. Napoleão Nunes Maia Filho. j.20.08.2009. 
Tal situação é preocupante, especialmente por se estar diante de situação definidora da intervenção ou não do ramo mais agressivo do Direito. Daí a importância do tema.

De qualquer forma, nessa busca perversa por uma verdadeira positivação que possa servir de norte aos julgadores, especificamente no tocante à questão da insignificância, o que hoje se verifica é que tem prevalecido em âmbito jurisprudencial decisões baseadas em um acórdão emanado da nossa mais alta Corte. Faz-se referência ao julgamento do Habeas Corpus n ${ }^{\circ}$ 84.412-0/SP, Rel. Min. Celso de Mello, a partir do qual o Supremo Tribunal Federal passou a se valer de alguns critérios alçados à condição de "vetores de aplicação do princípio da insignificância". Eis o teor da ementa do julgado em questão:

Ementa: Princípio da Insignificância - Identificação dos vetores cuja presença legitima o reconhecimento desse postulado de política criminal - Conseqüente descaracterização da tipicidade penal em seu aspecto material - Delito de furto - Condenação imposta a jovem desempregado, com apenas 19 anos de idade - "Res furtiva" no valor de $\mathrm{R} \$ 25,00$ (equivalente a $9.61 \%$ do salário mínimo atualmente em vigor) - Doutrina - Considerações em torno da jurisprudência do STF - Pedido deferido.

O princípio da insignificância qualifica-se como fator de descaracterização material da tipicidade. O princípio da insignificância - que deve ser analisado em conexão com os postulados da fragmentariedade e da intervenção mínima do Estado em matéria penal - tem o sentido de excluir ou de afastar a própria tipicidade penal, examinada na perspectiva de seu caráter material. Doutrina. Tal postulado - que considera necessária, na aferição do relevo material da tipicidade penal, a presença de vetores, tais como (a) a mínima ofensividade da conduta do agente, (b) a nenhuma periculosidade social da ação, (c) o reduzidíssimo grau de reprovabilidade do comportamento e (d) a inexpressividade da lesão jurídica provocada - apoiou-se, em seu processo de formulação teórica, no reconhecimento de que o caráter subsidiário do sistema penal reclama e impõe, em função dos princípios objetivos por ele visados, a intervenção mínima do Poder Público. 
O postulado da insignificância e a função do direito penal: "de minimis, no curat praetor". O sistema jurídico há de considerar a relevantíssima circunstância de que a privação da liberdade e a restrição de direitos do indivíduo somente se justificam quando estritamente necessárias à própria proteção das pessoas, da sociedade e de outros bens jurídicos que lhes sejam essenciais, notadamente naqueles casos em que os valores penalmente tutelados se exponham a dano, efetivo ou potencial, impregnado de significativa lesividade. $O$ direito penal não se deve ocupar de condutas que produzam resultados, cujo desvalor - por não importar em lesão significativa a bens jurídicos relevantes - não represente, por isso mesmo, prejuízo importante, seja ao titular do bem jurídico tutelado, seja à integridade da própria ordem social (HC 84.412-0/SP. Rel. Min. Celso de Mello. j.19.10.2004).

Tal qual referido, a partir de tal julgado formou-se uma verdadeira rede de decisões, invariavelmente sem qualquer questionamento do próprio acórdão em $\mathrm{si}^{7}$. É dizer, tais "vetores", tanto para o próprio Supremo ${ }^{8}$

7 Por exemplo, no HC 90747/PR, Relator o Min. Joaquim Barbosa, publicado no DJ de 17/12/2009, assim ementado: "Habeas corpus. Exacerbação da pena-base e aplicação de causa de aumento de pena. Fundamentação. Ocorrência. Necessidade de reexame dos elementos fáticos. Inviabilidade. Súmula $n^{\circ} 719$ desta Corte. Incidência. Princípio da Insignificância. Vetores caracterizadores não supridos. Precedentes. Não há violação ao art. 93, inc. IX, da Constituição Federal, quando é fixada a pena-base acima do mínimo legal e adota-se, para tanto, a fundamentação desenvolvida pelo juiz sentenciante acerca das circunstâncias judiciais desfavoráveis concretamente consideradas à luz do fatocrime praticado. Não cabe reexaminar, no âmbito do remédio heróico, os elementos de convicção essenciais ao estabelecimento da sanção penal, porque necessária, para tanto, a concreta avaliação das circunstâncias de fato subjacentes aos critérios legais que regem a operação de dosimetria da pena. Precedentes. A via estreita do processo do "habeas corpus" não permite que nele se proceda à ponderação exaustiva das circunstâncias referidas no art. 59 do Código Penal. A imposição do regime de cumprimento mais severo do que a pena aplicada permitir exige motivação idônea. Enunciado da Súmula $n^{\circ}$ 719. Para a aplicação do princípio da insignificância, é necessária, na aferição do relevo material da tipicidade penal, a inequivoca constatação de seus vetores, que são (a) a mínima ofensividade da conduta do agente, (b) a ausência de periculosidade social da ação, (c) o reduzidíssimo grau de reprovabilidade do comportamento e (d) a inexpressividade da lesão jurídica provocada. Precedentes. Ordem denegada".

8 Neste sentido: HC 94.524-4/DF. Rel. Min. Eros Grau. j.24.06.2008; HC 95.445-6/ DF. Rel. Min. Eros Grau. j.02.12.2008; HC 93.393-9/RS. Rel. Min. Cesar Peluzo. 
quanto para os demais Tribunais ${ }^{9}$, passaram a serem vistos como portos seguros de hipóteses em que se mostraria devida a aplicação da regra da insignificância.

Se por um lado tal situação teria a vantagem de dar coerência à aplicação da regra em questão, por outro tem gerado uma verdadeira alienação de interpretação. Isto é, um engessamento que, não bastassem os riscos que por si só representa, tem se mostrado equivocado, mormente quando se identifica incongruências dentro do próprio acórdão paradigmático.

De fato, uma análise mais atenta do acórdão em questão evidencia que, muito embora sua ementa trace os tais "vetores", carece o voto do eminente Ministro Relator da devida fundamentação quanto ao que consistiu cada um dos vetores referidos. Ademais, evidencia-se que, conforme disposto no acórdão, a "mínima ofensividade da conduta do agente" estaria relacionada a um percentual do salário mínimo então em vigor. Ainda, seguindo uma tendência tradicional do direito criminal (atualmente, ultrapassada), ignora-se por completo a figura da vítima e da disponibilidade que esta tenha sobre o bem jurídico atingido, daí não se fazer qualquer referência ao que representava para a vítima aquele "percentual do salário mínimo então em vigor". Tais circunstâncias, por si só, põem em dúvida a legitimidade de o referido acórdão servir de paradigma para a aplicação da regra em questão.

Advirta-se, não se estar a discutir se, no caso concreto do $\mathrm{HC}$ 84.412-0/SP, se mostrava devido o reconhecimento da insignificância. $\mathrm{O}$ que se discute é a legitimidade de se transformar referido julgado em paradigma para a aplicação da regra da insignificância, mormente se identificado que, no corpo de seu texto, há incongruências entre a ementa - que vem sendo utilizada por vezes de forma cega e positiva - e a fundamentação do acórdão, conforme referido.

j.14.04.2009.

9 Neste sentido: REsp 835.553/RS. Rel. Min. Laurita Vaz. j.20.03.2007. 


\subsection{Deve Haver Critérios?}

Antes de discutir os critérios escolhidos pelo Supremo Tribunal Federal, cumpre referir à necessidade ou não do estabelecimento deles. Não apenas porque a existência de critérios jurisprudenciais fechados engessa a evolução social do tema, passando das discussões à mera submissão ao precedente, mas também fundamentalmente pela própria relação política do princípio.

Se o princípio de intervenção mínima deriva da ideia de necessidade e se as necessidades sociais são cambiantes, conforme a evolução da própria sociedade, resulta imprescindível que, em havendo critérios, estes sejam abertos ou permeáveis à própria evolução social.

Assim, na fórmula adotada por Muñoz Conde e Arán (2002, p. 72) de entender que o Direito penal só deve intervir contra os ataques mais graves aos bens jurídicos mais importantes para o desenvolvimento do ser humano em sociedade, temos que os critérios são absolutamente abertos.

Ataques mais graves é um critério composto por um referencial. Se há o que é mais grave, há o menos grave. A referência é comparativa. Ou seja, por um lado se deixa clara a possibilidade de existência de outra classe de ataques ao bem jurídico cuja comparação gradativa em uma escala de gravidade admite abrir mão da intervenção penal especificamente quando outra forma de intervenção menos gravosa seja possível, em evidente expressão da ideia de subsidiariedade. Por outro, quando se fala em gravidade, esta pode referir-se tanto a aspectos quantitativos como qualitativos, abrindo ampla margem de interpretação. A referência a ataques, por sua vez, deixa clara a exigência de uma expressão externa, própria da vida de relação, como pré-requisito da intervenção.

O estabelecimento da limitação aos bens jurídicos mais importantes, também implica uma escala gradativa qualitativa, agora relacionada com os bens jurídicos objeto do ataque criminoso. Assim, dota-se de permeabilidade a eventual aflição de bens jurídicos que não obrigue à tradução em reação jurídico-penal. Essa fórmula expressa claramente a ideia de fragmentariedade, compreendida como a desnecessidade de cobertura absoluta do sistema de intervenção jurídico-penal. 
O próprio conceito de bem jurídico é reconhecido pela doutrina como um conceito aberto, cuja indefinição é justamente o que permite a abertura para a introdução da evolução social, segundo afirmam os autores Roxin (1997, p. 71), Hassemer e Muñoz Conde (1989, p. 106-107) e Tavares (2004, p.39). Essa abertura conceitual, se por um lado torna este um dos campos mais discutidos na dogmática moderna, por outro, é o que o valida como conceito, já que permite a oxigenação permanente do sistema de imputação com valores culturalmente admitidos pela evolução humana. O sacrifício absoluto da referência ao bem jurídico em prol da segurança jurídica de um sistema fechado leva, por vezes, ao sacrifício do critério de justiça, em torno do qual se desenvolve todo o direito e, portanto, não é aceitável.

Tudo a indicar, portanto, que se pretende a adoção de critérios - ou vetores como quer o Supremo Tribunal Federal - que eles sejam abertos e permeáveis às evoluções da sociedade, reconhecendo-se, ademais, a importância da função exercida pelo intérprete na construção e no aprimoramento da Ciência Jurídica.

\subsection{Os Critérios Escolhidos}

Analisando, porém, os "vetores" elencados pela nossa Corte Suprema, o que se percebe é que os critérios referidos, de larga aceitação acadêmica, não foram precisamente os adotados. Tal qual citado, o elenco firmado pelo Supremo Tribunal Federal consubstancia-se em quatro critérios. No seu dizer:

a) a mínima ofensividade da conduta do agente;

b) a nenhuma periculosidade social da ação;

c) o reduzidíssimo grau de reprovabilidade do comportamento; e

d) a inexpressividade da lesão jurídica provocada.

Pois bem, conforme mencionado, o objeto do presente estudo prende-se especificamente à análise da pertinência do primeiro desses critérios, isto é, a "mínima ofensividade da conduta do agente". Basicamente, 
o que se indaga é até que ponto o desvalor da conduta do agente pode ser utilizado como critério de aplicação do princípio da intervenção mínima.

Claro que todo o delito se equilibra em um desvalor de conduta e um desvalor de resultado. Conquanto isso seja mais evidente no âmbito do resultado, também o desvalor da conduta está associado a um bem jurídico, já que nem todas as condutas são juridicamente relevantes, menos ainda jurídico-penalmente relevantes.

Assim, a primeira tarefa parece ser a de identificação do que é uma conduta jurídico-penalmente relevante.

Essa tarefa remete essencialmente ao conceito jurídico penal de conduta ou ação. Nesse sentido, é importante afirmar que o conceito jurídico de ação ou conduta não tem por que ser idêntico ao conceito físico de conduta, assim como outros conceitos jurídicos não coincidem ipsis litteris com seu coincidente físico ${ }^{10}$. Aliás, não é demais observar que a ideia de um conceito ontológico de conduta em Direito penal é completamente ultrapassada no âmbito doutrinário das matrizes europeias, conforme Busato (2005, p. 69), ainda que siga vagando moribunda em cada vez mais escassas vozes doutrinárias brasileiras. Essa circunstância é derivada da demolidora crítica sofrida pelo finalismo como doutrina da ação ${ }^{11}$ à raiz do trabalho de Roxin (1998, p. 91).

10 Assim, por exemplo, o conceito de morte, que no âmbito das ciências naturais, por exemplo, a medicina, jamais admitiriam uma modalidade presumida, tal como expresso no artigo $7^{\circ}$ do Código Civil brasileiro: Art. $7^{\circ}$ Pode ser declarada a morte presumida, sem decretação de ausência: I - se for extremamente provável a morte de quem estava em perigo de vida; II - se alguém, desaparecido em campanha ou feito prisioneiro, não for encontrado até dois anos após o término da guerra. Parágrafo único. A declaração da morte presumida, nesses casos, somente poderá ser requerida depois de esgotadas as buscas e averiguações, devendo a sentença fixar a data provável do falecimento.

11 Importante notar que o finalismo é um termo utilizado tanto para designar uma fórmula de organização e distribuição das categorias do delito, quanto para designar uma teoria da ação. Isso deriva de que quando do advento da proposta de adoção de uma ação finalista por Welzel (2003), dessa concepção derivavam alterações sensíveis na distribuição dos elementos componentes do conceito de delito em face da teoria até então dominante. $\mathrm{O}$ finalismo era, e sempre foi, antes de tudo, uma teoria da ação. Assim, é possível afirmar que como teoria da ação, o finalismo está completamente superado, ainda que, como fórmula de distribuição das categorias na teoria do delito siga sendo dominante. A prova 
Dentro das inúmeras tendências de superação do conceito ontológico de ação em direito penal, desponta como maior destaque o conceito significativo de ação. Isso por duas fundamentais razões: o avanço científico da teoria de base de onde arranca, que é a filosofia da linguagem e, ao mesmo tempo, seu perfeito ajuste ao cotidiano da praxis forense.

Dentro desse modelo, a ação é reconhecida como um sentido normativo e não um substrato ontológico. Ação e omissão são situações identificadas e compreendidas contextualmente, segundo a determinação das circunstâncias. Em termos penais, é possível dizer que a ação é o sentido de um substrato típico, pois a tarefa do intérprete se resume a identificar se as circunstâncias averiguadas transmitem um contexto de conduta (ação ou omissão) correspondente a um tipo, pois o tipo compõe o standard, o modelo, cujo sentido busca-se compreender como presente ou ausente no contexto exarado pelas circunstâncias.

Assim, fala-se já em tipo de ação ou tipo de omissão e não simplesmente em ação ou omissão. O tipo de ação ou omissão compreende uma pretensão conceitual de relevância, pois expressa que, de algum modo, houve atuação concreta de um sujeito no sentido da determinação de um fato típico.

No entanto, na estrutura de distribuição das categorias do delito que brota do conceito significativo de ação, a presença de um tipo de ação ainda não significa que o fato seja relevante a ponto de pretender-se a aplicação da norma ao caso concreto.

É que resulta necessário reconhecer que a teoria do delito nada mais é do que a distribuição de tópicos que funcionam como filtros gerais do reconhecimento da pretensão de validade e legitimidade da norma para a produção de seus efeitos, como afirma Vives Antón (1996, p. 481-482); e, ainda segundo esse autor, a estruturação teórica do delito não visa à produção de um resultado verdadeiro (daí que não é ciência, e sim mera técnica argumentativa), mas apenas um resultado justo. Essa pretensão de justiça deriva da aplicação de uma norma em correspondência com o sen-

mais cabal disso é que tal fórmula é seguida pela maioria dos autores que não defendem mais um conceito de ação finalista em sentido ontológico. 
tido de uma ação. Assim, a realização, sabidamente utópica, da pretensão de justiça se expressa nas subpretensões de validade normativa frente ao caso concreto, através da estruturação da teoria do delito.

Em função desse modelo teórico, Vives Antón propõe que o reconhecimento da existência do crime e, portanto, da validade da norma para a realização de pretensão de justiça em face do sentido de ação ou omissão perpetrado se expresse primeiramente através de uma pretensão de relevância. É necessário saber se a norma pode pretender a afirmação de sua relevância para o caso concreto; em seguida, afere-se a pretensão de ilicitude, que traduz a pretensão de que a norma possa afirmar ser a ação em questão um ilícito; em seguida, há de corresponder a uma pretensão de reprovação pessoal em face do autor; finalmente, a norma deve representar a pretensão de aplicação de uma pena, uma pretensão de punibilidade.

Dessas todas subpretensões, a primeira delas, a pretensão de relevância deve expressar uma dupla dimensão: uma pretensão conceitual de relevância, ditada pela correspondência entre o modelo típico e a expressão de sentido da ação analisada, limitada, portanto, pelo catálogo dos tipos penais e uma pretensão de ofensividade, revelada pela expressão de sentido de ofensa grave a um bem jurídico importante para o desenvolvimento social da vítima.

Claro está que uma norma só pode afirmar sua pretensão de relevância em face do caso concreto, ou seja, afirmar que sua aplicação é relevante no contexto analisado, a partir de que a ação seja uma expressão de sentido correspondente a um tipo, momento em que se expressa o princípio de legalidade, e se a ação também expressa uma ofensa a um bem jurídico suficientemente importante para receber dimensão penal, garantindo, assim, o princípio de intervenção mínima.

Assim, a conduta deve expressar tal ofensa em gravidade suficiente para que se reconheça a presença da pretensão de relevância, primeiro atributo da norma na configuração da teoria do delito. A mínima ofensividade da conduta, portanto, primeiro critério de aferição defendido pelo Supremo Tribunal Federal, compreende, na verdade, ou toda a expressão do princípio de intervenção mínima ou um completo vazio. 
Isso porque, compreendida a ação como expressão de sentido, dizer que a conduta é dotada de uma ofensividade mínima pode ser compreendido de duas formas: ou estamos dizendo que é efetivamente mínima a ofensividade, o que quer dizer que a ofensividade não pode ser menor do que a representada pela conduta, ou entendemos que há alguma ofensividade, ainda que mínima, sendo possível existir, em uma conduta, nenhuma ofensividade.

No primeiro caso, entendendo a ofensividade mínima da conduta como o limite mínimo, ou seja, entendendo que não é possível ser menos ofensivo do que a conduta em concreto foi, temos que aí já estaria representada a totalidade do princípio de intervenção mínima, posto que ausente a pretensão de ofensividade, ou seja, a conduta não teria expressado o sentido de qualquer ofensa ao bem jurídico.

Resultaria, pois, um completo despropósito analisar ideias como a nenhuma periculosidade social da ação, já que a ação que guarda ofensividade mínima, não sendo relevante para o bem jurídico, não tem periculosidade social alguma. Do mesmo modo, não faria sentido analisar o reduzidíssimo grau de reprovabilidade do comportamento, posto que um comportamento que não é ofensivo para bens jurídico não pode ser reprovável desde um ponto de vista penal. Finalmente, careceria de sentido discutir a inexpressividade da lesão jurídica provocada, porque a lesão jurídica decorreria justamente da expressão de sentido da ação perpetrada, que já, por si, teria sido reconhecida como de periculosidade nula.

Dando a segunda interpretação possível ao conceito de ofensividade mínima da conduta, ou seja, entendendo ter havido alguma ofensa, de caráter mínimo, mas não nula, é necessário lembrar que se está fazendo uma análise dentro do campo penal. Ora, a análise da pretensão de ofensividade não se dá em graus de intensidade, mas sim com vistas à afirmação de sua relevância. Portanto, entendida como existente alguma ofensividade, a ponto de representar uma expressão de sentido do ponto de vista penal, estaria presente a pretensão de relevância, ou, na terminologia tradicional, estaria afirmado materialmente o tipo. Dessarte, a presença de uma ofensividade mínima ou ofensividade máxima, seria matéria reservada para a quantificação da pena e jamais para a afirmação do crime, o que conduz à completa inutilidade do critério. 
Desse modo, a primeira questão a definir é como interpretar a ideia de ofensividade mínima. Parece mais adequado, sob pena de trabalhar com um critério ou conceito absolutamente inútil, que se leve em conta que o que se pretende transmitir é a ideia penal de relevância material, ou seja, entender-se que há uma ofensividade mínima implicaria o afastamento do tipo de ação por carência da pretensão de ofensividade e logo, da pretensão de relevância da ação como expressão de sentido material de um tipo penal.

Restaria, ainda, ver o que exatamente pode significar o desvalor de conduta em sentido penal.

\subsection{0 que Deve e o que não Pode ser Entendido por Desvalor de Conduta}

Nesse aspecto, é importante perceber que se está falando de uma expressão de sentido, ou seja, que uma ação é mais do que simplesmente um movimento físico, pois é uma expressão que traduz a atuação de alguém em função de uma proposição que realiza algo relevante.

Assim, é fundamental firmar alguns limites que, conquanto não pretendam esgotar o tema, podem servir de tópicos iniciais para discussão.

O primeiro deles é a significação concreta do desvalor da conduta, como expressão do realizado. Ou seja, quando se fala da conduta, trata-se de uma expressão de sentido, daquilo que é realizado nos autos, daquilo que se pretende ver reconhecido como objeto válido da pretensão normativa de realização do justo; isto é, ficam fora aqui outros aspectos ou interpretações que se possa dar ao termo conduta. Com conduta, não se está expressando um modo cotidiano de proceder, um modus vivendi, mas sim, concretamente, uma ação ou omissão que se expressa com o sentido de um tipo ou não. Não interessa o modo de vida do agente, o seu passado ou o que quer que tenha realizado antes, nem mesmo o modo como leva a vida. Isso não pertence à afirmação de que se trata de um crime.

Pensar o contrário significa claramente optar por um direito penal de autor em detrimento de um direito penal do fato. 
Em segundo lugar, é fundamental diferenciar entre ações e atos como expressão de conduta.

Quando se faz referência à conduta se trata de um proceder global, circunstanciado, muitas vezes levada a efeito através de vários atos. Assim, o contexto global do sentido de uma ação ou omissão faz denotar, precisamente, que a ideia, por exemplo, de crime continuado não é, ao contrário do que afirma a doutrina tradicional, uma ficção. Somente poderia ser ficção se adotado um conceito de ação que não pertence ao Direito, mas à Física. Um conceito ontológico que, ademais, tem imensa dificuldade de separar ação e ato. De um ponto de vista físico, resulta completamente impossível afirmar uma ação de dirigir e infirmar que seja uma ação, trocar as marchas, pisar no freio ou buzinar. De um ponto de vista normativo, ao contrário, compreende-se que todos eles são atos que compõem a ação de dirigir que, realizada no contexto da provocação imprudente de um acidente, representará um tipo de ação.

Essa compreensão normativa da conduta é fundamental para a compreensão de situações como a do delito de acumulação que, se por um lado encontra barreira no princípio de culpabilidade ${ }^{12}$, quando consiste em uma repetição de violação de um mesmo bem jurídico de uma mesma vítima, realizada por um mesmo autor em escala sucessiva, poderá ser considerada uma única conduta como expressão de sentido típico e ter, aí mesmo, medido o seu grau de ofensividade, para fins de afirmação ou de negação da existência de um delito.

\section{Conclusões}

Em conclusão, poder-se-ia afirmar em primeiro lugar a necessidade de que a jurisprudência defina concretamente sua interpretação a respeito do conceito de ação, fazendo-o através da adoção de um conceito normativo, em obediência às tendências dogmáticas modernas.

\footnotetext{
12 Sim, porque, se várias pessoas realizam condutas similares contra uma mesma vítima, de modo a que cada qual desconheça a atitude alheia, ninguém poderá responder pela culpabilidade derivada da atitude do outro.
} 
Também parece possível pretender ver resolvida a aparente inconsistência da expressão mínima ofensividade da conduta, visando deixar claro se está presente uma situação de absoluto afastamento de interesse penal, porque a ofensa deu-se contra um bem jurídico indigno de proteção penal, ou porque o ataque a um bem jurídico relevante foi demasiado leve para justificar a intervenção penal, ou se estamos apenas diante de uma ofensa que, conquanto efetivamente expressa um sentido de relevância, foi de escassa magnitude. Não é demais repisar que dessa definição depende inclusive a utilidade mínima do critério em apreço.

A partir da fixação dessas premissas especialmente se afirmada alguma utilidade do critério de minima ofensividade da conduta, incumbe discutir, tanto no campo teórico, quanto da praxis forense quais os limites interpretativos dessa expressão, tanto para evitar uma tendência a um direito penal de autor, quanto para resolver problemas relacionados com os delitos de acumulação, sem prejuízo de outras implicações que ainda estejam por ser identificadas.

\section{Referências}

ALEXY, Robert. Teoría de los derechos fundamentales. Trad. Ernesto Garzón Valdés, Madrid: Centro de Estudios Políticos y Constitucionales, 2002.

ANDRADE, Vera Regina Pereira. A Ilusão de Segurança Jurídica. 2. ed. Porto Alegre: Livraria do Advogado, 2003.

BUSATO, Paulo César; MONTES HUAPAYA, Sandro. Introdução ao Direito Penal. Bases para um sistema penal democrático. 2. ed. Rio de Janeiro: Lumen Juris, 2007.

BUSATO, Paulo César. Direito penal e ação significativa. Rio de Janeiro: Lumen Juris, 2005.

DAVID, René. O direito inglês. São Paulo: Martins Fontes, 2000.

DWORKIN, Ronald. Levando os direitos a sério. Trad. Nélson Boeira. São Paulo: Martins Fontes, 2002. 
FERRAJOLI, Luigi. Razones Jurídicas del Pacifismo. Trad. de Perfecto André Ibañez, Gabriel Ignacio Anitúa, Marta Monclús Masó e Gerardo Pisarello, Madrid: Trotta, 2004.

FERRAZ JÚNIOR, Tércio Sampaio. Teoria da Norma Jurídica. 3. ed. Rio de Janeiro: Forense, 1997.

HASSEMER, Winfied; MUÑOZ CONDE, Francisco. Introducción a la Criminología y al Derecho penal. Valencia: Tirant lo Blanch, 1989.

MAYER, Max Ernst. Normas Jurídicas y Normas de Cultura. Trad. José Luis Guzmán Dabora. Buenos Aires: Hammurabi, 2000.

MUÑOZ CONDE, Francisco; GARCÍA ARÁN, Mercedes. Derecho Penal. Parte General. 5. ed. Valencia: Tirant lo Blanch, 2002.

RADBRUCH, Gustav. EI Espíritu del Derecho Inglés. Trad. Juan Carlos Peg Ros: Madrid: Marcial Pons, 2001.

DAVID, René. O direito inglês. São Paulo: Martins Fontes, 2000.

ROTHENBURG, Walter Claudius. Princípios constitucionais. Porto Alegre: Sérgio Fabris Editor, 1999.

ROXIN, Claus. Contribuição para a crítica da teoria finalista da ação. In: Problemas fundamentais de Direito penal. Trad. Ana Paula dos Santos Luís Natcheradetz. 3. ed. Lisboa: Vega, 1998.

ROXIN, Claus. Derecho penal. Parte General. Tomo I. Trad. DiegoManuel Luzón Peñz, Miguel Díaz y García Conlledo e Javier de Vicente Remesal. Madrid: Civitas, 1997.

TAVARES, Juarez E. X. Bien jurídico y Función en Derecho Penal. Trad. Mônica Cuñarro. Buenos Aires: Hammurabi, 2004.

VIVES ANTÓN, Tomás S. Fundamentos del Sistema Penal. Valencia: Tirant lo Blanch, 1996.

WELZEL, Hans. Direito Penal. Trad. Afonso Celso Rezende. Campinas: Romana, 2003. 